\title{
High Frequency Neuromagnetic Signals: A New Biomarker for Localizing Epileptic Areas Running Title: High-Frequency Neuromagnetic Signals in Epilepsy
}

\author{
Xiang $\mathrm{J}^{1^{*}}$, Leiken $\mathrm{K}^{1}$, Wu $\mathrm{C}^{2}$, Wang $\mathrm{X}^{2}$, Fan $\mathrm{Y}^{3}$, Qi $\mathrm{L}^{4}$ and Qiao $\mathrm{H}^{4}$ \\ ${ }^{1}$ MEG Center, Division of Neurology, Cincinnati Children's Hospital Medical Center, Cincinnati, OH, USA \\ ${ }^{2}$ Department of Neurology, Nanjing Brain Hospital, Nanjing, People's Republic China \\ ${ }^{3}$ Department of Pediatric, Shengjing Hospital, Shenyang, People's Republic China \\ ${ }^{4}$ MEG Laboratory, Tiantan Hospital, Beijing, People's Republic of China
}

"Corresponding author: Xiang J, Division of Neurology, Cincinnati Children's Hospital Medical Center 3333, Burnet Avenue, Cincinnati, OH, 45220, USA, Tel: 1-513-636-6303, Fax: 1-513-636-1888; E-mail: Jing.xiang@cchmc.org

Received date: Oct 20, 2016; Accepted date: Oct 21, 2016; Published date: Oct 26, 2016

Copyright: (c) 2016 Xiang J, et al. This is an open-access article distributed under the terms of the Creative Commons Attribution License, which permits unrestricted use, distribution, and reproduction in any medium, provided the original author and source are credited.

\section{Editorial}

Approximately $20-30 \%$ of epilepsy cases are intractable to medical therapy [1-4]. There are 400,000 to 600,000 patients with refractory epilepsy in the United States $[5,6]$. For these patients, surgical removal of the brain regions causing the seizures is a necessity. Unfortunately, epilepsy surgery is offered to only $2-3 \%$ of potential surgical candidates in the United States [7-9]. This is because many patients are not considered candidates for surgical management because a single region causing the seizures (ictogenic zone) cannot be identified $[4,8,9]$. Although epilepsy surgery is expensive and the overall costs of surgical or medical management are similar in the first 2 years, patients who achieve seizure freedom after surgery have significantly lower costs compared with those treated with medication over the long-term $[1,10]$. The impact of intractable epilepsy extends far beyond seizures themselves. It is accompanied by poorer quality of life and a variety of comorbidities, including sudden unexpected death [1-4]. Epilepsy surgery is one potential cure $[4,11]$. Accurate identification of the ictogenic zones is essential to ensure a favorable surgical outcome [12]. This identification often necessitates:

- Invasive surgical electrode placement upon the brain surface to capture epileptogenic spikes $(14-70 \mathrm{~Hz})$ and seizures with electrocorticography (ECoG) $[1,12-15]$ and

- Consequent return to the operating room for surgical removal of the ictogenic zones after days (or weeks) of ECoG data collection $[1,12-15]$. Such invasive and costly procedures are associated with morbidity and potential mortality.

Magnetoencephalography (MEG) is a technique that can be used to localize ictogenic zones and guide ECoG electrode implantation $[16,17,22]$. Ideally, non-invasive MEG will replace invasive ECoG [18-21], but proof of its reliability is still lacking [22]. Recent success in localizing high-frequency brain signals (HFBS, 70-2,500 Hz) using MEG opens a new window for reliably localizing ictogenic zones [16,23-27]. HFBS in epilepsy are also called High Frequency Oscillations (HFOs), ripples, fast ripples. Since localization of ictogenic zones with MEG is noninvasive [16,26], the localization of HFBS with MEG, or high frequency neuromagnetic signals, will minimize the risk and decrease the cost of epilepsy surgery, and result in more seizure freedom for intractable epilepsy patients in the future.

Although HFOs or ripple, fast ripples can record with intracranial recordings in epilepsy [28-31], it has significant limitation. Specifically, intracranial recordings are typically done with micro- or macroelectrode EEG placed within the scalp. Those recordings are also called intracranial EEG (iEEG), or ECoG [28-31]. The placement of electrodes require risky surgery, it is very invasive. Another method for recording HFOs is Stereo Electroencephalographic (SEEG) [32]. Although SEEG may be less risky as compared with iEEG or ECoG, it is still a very invasive procedure. MEG, one of the relatively new technologies, is much safer as compared with intracranial recordings.

Recent reports have shown that HFBS can also record with scalp Electrophotography (EEG) [33-40]. Scalp EEG is a non-invasive procedure as compared with intracranial recordings. However, the scalp EEG is characterized with "low-pass effect" [41], which means that low frequency electrical signals can pass through the brain, skull and scalp and skin without significant decay of signals, while high frequency electrical signals have difficulty to pass through the brain, skull, scalp and skin without significant decay of signals power. In other words, there is frequency dependence of the transmission of the EEG from cortex to scalp. It has been found that during paralysis, frequencies over $20 \mathrm{~Hz}$ show powers of 10-200 times the power of those frequencies in the unparalyzed state. These high powers have actually been shown in some cases to originate in EMG as opposed to EEG data. Although in some situations the bulk of high frequencies are EMG-related, some studies have successfully recorded HFOs from scalp EEG [34,40], some showing continuous spike-waves during interictal slow-wave sleep [40], and some with simultaneous scalp EEG and intracranial recordings [34]. These scalp HFOs are associated with spatially limited focal subdural sources. Interestingly, the rates of HFOs are higher inside than outside the SOZ [42], and when used for determining SOZs are more precise than spikes $[43,44]$. Nevertheless, the reliability of scalp EEG detection of HFOs has remained an open question. Recent data showed that MEG is superior to EEG in the detection of HFBS [45].

In summary, one of the most research areas is to improve the outcomes of epilepsy surgery by using cost-efficient and noninvasive biomarkers of epileptogenicity that have the potential of replacing more expensive and invasive procedures. It is more than likely that multi-frequency analyses of neuromagnetic HFBS and spikes, instead of analysis of spikes alone, will lead to much better localization of ictogenic zones and result in significantly improved rates of seizure freedom. We consider the future of the study of neuromagnetic HFBS is bright for several reasons: 
Citation: Xiang J, Leiken K, Wu C, Wang X, Fan Y, et al. (2016) High Frequency Neuromagnetic Signals: A New Biomarker for Localizing Epileptic Areas Running Title: High - Frequency Neuromagnetic Signals in Epilepsy. Epilepsy J2 : e113. doi: $10.4172 / 2472-0895.1000 \mathrm{e} 113$

Page 2 of 3

- The occurrence of conventional spikes does not correlate with seizure severity (e.g., number of daily seizure) [46] but HFBS do correlate [47,48].

- Removal of brain regions generating HFBS has shown increased postoperative seizure freedom $[21,49]$ and

- New MEG methods, which utilize both spikes and HFBS, can localize ictogenic zones interictally [50,51].

\section{References}

1. Oldham MS, Horn PS, Tsevat J, Standridge S (2015) Costs and Clinical Outcomes of Epilepsy Surgery in Children With Drug-Resistant Epilepsy. Pediatr Neurol 53: 216-220.

2. Olsson I, Danielsson S, Hedstrom A, Nordborg C, Viggedal G, et al. (2013) Epilepsy surgery in children with accompanying impairments. Eur J Paediatr Neurol 17: 645-650.

3. Vachhrajani S, de Ribaupierre S, Otsubo H, Ochi A, Weiss SK, et al. (2012) Neurosurgical management of frontal lobe epilepsy in children. J Neurosurg Pediatr 10: 206-216.

4. Health Quality O (2012) Epilepsy surgery: an evidence summary. Ontario health technology assessment series 12: 1-28.

5. Moroni F, Nobili L, Curcio G, De Carli F, Fratello F, et al. (2007) Sleep in the human hippocampus: a stereo-EEG study. PLoS ONE 2: e867.

6. Enatsu R, Mikuni N (2016) Invasive Evaluations for Epilepsy Surgery: A Review of the Literature. Neurol Med Chir (Tokyo) 56: 221-227.

7. Cho-Hisamoto Y, Kojima K, Brown EC, Matsuzaki N, Asano E (2015) Gamma activity modulated by naming of ambiguous and unambiguous images: intracranial recording. Clin Neurophysiol 126: 17-26.

8. Craiu D, Barborica A, Motoescu C, Donos C, Ciurea J, et al. (2015) Presurgical Evaluation and Epilepsy Surgery in MRI Negative Resistant Epilepsy of Childhood with Good Outcome. Turkish neurosurgery 25: 905-913.

9. Boido D, Kapetis D, Gnatkovsky V, Pastori C, Galbardi B, et al. (2014) Stimulus-evoked potentials contribute to map the epileptogenic zone during stereo-EEG presurgical monitoring. Hum Brain Mapp 35: 4267-4281.

10. Gopinath S, Roy AG, Vinayan KP, Kumar A, Sarma M, et al. (2015) Seizure outcome following primary motor cortex-sparing respective surgery for perirolandic focal cortical dysplasia. Int J surg 15: 01302-01303.

11. Ibrahim GM, Barry BW, Fallah A, Snead OC, Drake JM, et al. (2012) Inequities in access to pediatric epilepsy surgery: a bioethical framework. Neurosurg Focus 32: E2.

12. Rosenow F, Luders H (2001) Presurgical evaluation of epilepsy. Brain 124: 1683-1700.

13. de Munck JC, Goncalves SI, Mammoliti R, Heethaar RM, Lopes da Silva FH (2009) Interactions between different EEG frequency bands and their effect on alpha-fMRI correlations. Neuroimage 47: 69-76.

14. Zhan Z, Xu L, Zuo T, Xie D, Zhang J, et al. (2014) The contribution of different frequency bands of fMRI data to the correlation with EEG alpha rhythm. Brain Res 1543: 235-243.

15. Yuan H, Liu T, Szarkowski R, Rios C, Ashe J, et al. (2010) Negative covariation between task-related responses in alpha/beta-band activity and BOLD in human sensorimotor cortex: an EEG and fMRI study of motor imagery and movements. Neuroimage 49: 2596-2606.

16. Xiang J, Liu Y, Wang Y, Kirtman EG, Kotecha R, et al. (2009) Frequency and spatial characteristics of high-frequency neuromagnetic signals in childhood epilepsy. Epileptic Disord 11: 113-125.

17. Jung J, Bouet R, Delpuech C, Ryvlin P, Isnard J, et al. (2013) The value of magnetoencephalography for seizure-onset zone localization in magnetic resonance imaging-negative partial epilepsy. Brain 136: 3176-3186.

18. Niranjan A, Laing EJ, Laghari FJ, Richardson RM, Lunsford LD (2013) Preoperative magnetoencephalographic sensory cortex mapping. Stereotact Funct Neurosurg 91: 314-322.
19. Rampp S, Kaltenhauser M, Weigel D, Buchfelder M, Ingmar Blumcke I, et al. (2010) MEG correlates of epileptic high gamma oscillations in invasive EEG. Epilepsia 51: 1638-1642.

20. Fischer MJ, Rampp S, Scheler G, Stefan H (2008) Comment: A systematic review on MEG and its use in the presurgical evaluation of localizationrelated epilepsy. Epilepsy Res 82: 238-239.

21. Genow A, Hummel C, Scheler G, Hopfengartner R, Kaltenhauser M, et al (2004) Epilepsy surgery, resection volume and MSI localization in lesional frontal lobe epilepsy. Neuroimage 21: 444-449.

22. Stefan H, Rampp S, Knowlton RC (2011) Magnetoencephalography adds to the surgical evaluation process. Epilepsy Behav 20: 172-177.

23. Xiang J, Korman A, Samarasinghe KM, Wang X, Zhang F, et al. (2015a) Volumetric imaging of brain activity with spatial-frequency decoding of neuromagnetic signals. J Neurosci Methods 239: 114-128.

24. Tang L, Xiang J, Huang S, Miao A, Ge H, et al. (2016) Neuromagnetic highfrequency oscillations correlate with seizure severity in absence epilepsy. Clin Neurophysiol 127: 1120-1129.

25. Xiang J, Luo Q, Kotecha R, Korman A, Zhang F, et al. (2014) Accumulated source imaging of brain activity with both low and high-frequency neuromagnetic signals. Front Neuroinform 8: 57.

26. Xiang J, Wang Y, Chen Y, Liu Y, Kotecha R, et al. (2010) Noninvasive localization of epileptogenic zones with ictal high-frequency neuromagnetic signals. J Neurosurg Pediatr 5: 113-122.

27. Xiang J, Holowka S, Qiao H, Sun B, Xiao Z, et al. (2004) Automatic localization of epileptic zones using magnetoencephalography. Neurol Clin Neurophysiol 2004: 98.

28. Gloss D, Nolan SJ, Staba R (2014) The role of high-frequency oscillations in epilepsy surgery planning. The Cochrane database of systematic reviews 1: CD010235.

29. Srejic LR, Valiante TA, Aarts MM, Hutchison WD (2013) High-frequency cortical activity associated with postischemic epileptiform discharges in an in vivo rat focal stroke model. J Neurosurg 118: 1098-1106.

30. Haegelen C, Perucca P, Chatillon CE, Andrade-Valenca L, Zelmann R, et al. (2013) High-frequency oscillations, extent of surgical resection, and surgical outcome in drug-resistant focal epilepsy. Epilepsia 54: 848-857.

31. Engel J Jr, da Silva FL (2012) High-frequency oscillations - where we are and where we need to go. Prog Neurobiol 98: 316-318.

32. Kalitzin S, Zijlmans M, Petkov G, Velis D, Claus S, et al. (2012) Quantification of spontaneous and evoked HFO's in SEEG recording and prospective for pre-surgical diagnostics. Case study. Conf Proc IEEE Eng Med Biol Soc 2012: 1024-1027.

33. Chaitanya G, Sinha S, Narayanan M, Satishchandra P (2015) Scalp High Frequency Oscillations (HFOs) in absence epilepsy: An independent component analysis (ICA) based approach. Epilepsy Res 115: 133-140.

34. Zelmann R, Lina JM, Schulze-Bonhage A, Gotman J, Jacobs J (2013) Scalp EEG is not a Blur: It Can See High Frequency Oscillations Although Their Generators are Small. Brain Topogr 27: 683-704.

35. von Ellenrieder N, Beltrachini L, Perucca P, Gotman J (2014) Size of cortical generators of epileptic interictal events and visibility on scalp EEG. Neuroimage 94: 47-54.

36. Staba RJ, Stead M, Worrell GA (2014) Electrophysiological biomarkers of epilepsy. Neurotherapeutics. The journal of the American Society for Experimental NeuroTherapeutics 11:334-346.

37. Kakisaka Y, Alkawadri R, Wang ZI, Enatsu R, Mosher JC, et al. (2013) Sensitivity of scalp 10-20 EEG and magnetoencephalography. Epileptic Disord 15: 27-31.

38. von Ellenrieder N, Andrade-Valenca LP, Dubeau F, Gotman J (2012) Automatic detection of fast oscillations $(40-200 \mathrm{~Hz})$ in scalp EEG recordings. Clin Neurophysiol 123: 670-680.

39. Iwatani $\mathrm{Y}$, Kagitani-Shimono K, Tominaga K, Okinaga T, Kishima H, et al. (2012) Ictal high-frequency oscillations on scalp EEG recordings in symptomatic West syndrome. Epilepsy Res 102: 60-70.

40. Kobayashi K, Watanabe Y, Inoue T, Oka M, Yoshinaga H, et al. (2010) Scalp-recorded high-frequency oscillations in childhood sleep-induced electrical status epilepticus. Epilepsia 51: 2190-2194. 
Citation: Xiang J, Leiken K, Wu C, Wang X, Fan Y, et al. (2016) High Frequency Neuromagnetic Signals: A New Biomarker for Localizing Epileptic Areas Running Title: High - Frequency Neuromagnetic Signals in Epilepsy. Epilepsy J 2: e113. doi: $10.4172 / 2472-0895.1000 \mathrm{e} 113$

Page 3 of 3

41. Pfurtscheller G, Cooper R (1975) Frequency dependence of the transmission of the EEG from cortex to scalp. Electroencephalogr Clin Neurophysiol 38: 93-96.

42. Jacobs J, Zelmann R, Jirsch J, Chander R, Dubeau CE, et al. (2009) High frequency oscillations $(80-500 \mathrm{~Hz})$ in the preictal period in patients with focal seizures. Epilepsia 50: 1780-1792.

43. Andrade-Valenca L, Mari F, Jacobs J, Zijlmans M, Olivier A, et al. (2012) Interictal high frequency oscillations (HFOs) in patients with focal epilepsy and normal MRI. Clin Neurophysiol 123: 100-105.

44. Gotman J (2010) High frequency oscillations: the new EEG frontier? Epilepsia 51 Suppl 1: 63-65.

45. Xiang J, Leiken K, Tang L, Miao A, Wang X, et al. (2015b) High-Frequency Oscillations in Pediatric Epilepsy: Methodology and Clinical Application. Journal of Pediatric Epilepsy 4: 156-164.

46. Selvitelli MF, Walker LM, Schomer DL, Chang BS (2010) The relationship of interictal epileptiform discharges to clinical epilepsy severity: a study of routine electroencephalograms and review of the literature. J Clin Neurophysiol 27: 87-92.

47. Miao A, Tang L, Xiang J, Guan Q, Ge H, et al. (2014a) Dynamic magnetic source imaging of absence seizure initialization and propagation: a magnetoencephalography study. Epilepsy Res 108: 468-480.

48. Miao A, Xiang J, Tang L, Ge H, Liu H, et al. (2014b) Using ictal highfrequency oscillations $(80-500 \mathrm{~Hz})$ to localize seizure onset zones in childhood absence epilepsy: a MEG study. Neurosci Lett 566: 21-26.

49. Rampp S, Stefan H (2007) Magnetoencephalography in presurgical epilepsy diagnosis. Expert review of medical devices 4: 335-347.

50. Xiang J, Korostenskaja M, Molloy C, deGrauw X, Leiken K, et al. (2016) Multi-frequency localization of aberrant brain activity in autism spectrum disorder. Brain Dev 38: 82-90.

51. Leiken K, Xiang J, Zhang F, Shi J, Tang L, et al. (2014) Magnetoencephalography detection of high-frequency oscillations in the developing brain. Front Hum Neurosci 8: 969. 